\title{
Strategic Entrepreneurship Based Model of Catch-up University in Global Rankings
}

\author{
Mikhail Kozlov ${ }^{1, *}$ \\ ${ }^{1}$ Moscow Technological Institute, 199334, Moscow, Russia
}

\begin{abstract}
The paper will help answer the question, why only few universities managed to succeed significantly in their global ranking advancement, while most of their competitors fail. For this purpose it will introduce a new strategically entrepreneurial catch-up university framework, based on the combination of the resource based view, dynamic capabilities, strategic entrepreneurship and latecomer organization concepts. The new framework logics explains the advantages of being ambidextrous for ranking oriented universities and pursuing new potentially more favorable opportunities for research development. It will propose that substantial increase in the level of dynamic capabilities of the universities and their resource base accumulation is based on the use of the new combination of financial, human and social capital combined with strategic management of these resources in the process of identification and exploitation of greater opportunities.
\end{abstract}

\section{Introduction}

International university rankings represent a powerful mechanism transforming the field of higher education into a market of competing universities, whose customer value is identified with their performance in terms of their global market competitiveness that is current rankings positions, depending primarily on their research performance. Searching how to set up research universities that are capable of successfully keeping up with the leading academic institutions in the global race has become a priority for high education systems of most countries. Many of them initiated their programs of funding research development in their universities to make them more globally competitive, so that they could advance in international rankings. While only few universities managed to succeed so far in their ranking advancement, the question - why they were able to do so, while others fail - remains unanswered from the contemporary management point of view. The absence of management models of university competitiveness development can represent a substantial risk for such programs.

For development of the university competitiveness model some specific aspects of latecomers examined in [1] can be applied. Hazelkorn identified a number of particular sources of difficulties being equally applicable to the development of starting late both countries and universities in their environments of global competition. The difficulties arise because of "a poor resource base; undemonstrated capacity and operating outside important networks; policy and funding mechanisms which reinforce institutional imbalances; and human resources and industrial relations tensions specific to late development" [2]. Although the essence of the citation implies that the latecomer university (LCU) performance is to a greater extent resource base-constrained rather than market entry barriers-constrained, the main outcome of her analysis was that these difficulties act like barriers for LCU to entry. Thus, there is a gap in the sense that the uncovered analogy wasn't exploited for building resource-based model of LCU evolution.

The primary goal of this study is to bridge the gap and develop a conceptual model of LCU to uncover the distinctive factors of the LCU success in its competitiveness development.

The main contribution of this paper is that in search for strategic, innovation and entrepreneurial management instruments to resolve the cases of catchup success stories of LCU evolution, it introduces a new strategically entrepreneurial catch-up university framework, grounded on the combination of the resource-based view (RBV), dynamic capabilities (DC), strategic entrepreneurship (SE) and latecomer organization concepts. Another contribution of this paper is that it uncovers the roles of strategically entrepreneurial top managers and DC within a LCU framework and the importance of their availability for a success of LCU advancing in rankings.

The paper is divided into four sections. Following the introductory section, the second section discusses the RBV, DC and SE concepts. In the third section we discuss the model of LCU and the logic of a strategically entrepreneurial LCU construct linking the

Corresponding author: mkozlov@mbschool.ru 
concepts. The fourth section outlines most significant conclusions and suggests directions for future research.

\section{Resource-based view, dynamic capabilities and strategic entrepreneurship concepts}

The definition of catch-up organizations used in this article is built using RBV and DC frameworks. Their combination implies that "competition may be translated into the resource-based framework by considering the firms' new combinations of resources as a means to reach the goal of sustained competitive advantage following Schumpeter views of the competitive process as dynamic involving uncertainty, struggle and disequilibrium" [3].

The RBV main proposition is that it is organizationspecific resource base diversity, which is responsible for organizational performance heterogeneity. In RBV competitive advantage of an organization is caused by a difficult to imitate resource base that embraces its resources and capabilities. The capabilities, supplying an organization with distinct strategic advantages over its competitors, are regarded as core capabilities [4]. The efforts to overcome limitations of the RBV static nature and the difficulties in description of a firm's resource base evolutionary processes led to the development of the dynamic capabilities framework [3], [5], [6]. The definition of DC is "the firm's ability to integrate, build, and reconfigure internal and external competences to address rapidly changing environments" [3].

Three basic groups of factors, processes, positions and paths describe development of organizational capabilities embedded in the processes inside organization. The organizational processes involved in the development of organizational capabilities can perform three functions: coordination/integration, learning and reconfiguration.

These managerial and organization-specific processes, shaped by its resources and capabilities, position and its development path are responsible for the organization's ability to reach more innovative type of competitive advantage. DC are primarily located inside the organizational top management team, but are subject to the influence by the existing processes, systems, and structures that the organization has set up to run its activities beforehand. The ability of senior managers to seize opportunities through the orchestration and integration of both new and existing assets to overcome inertia and path dependencies is at the core of dynamic capabilities [7].

DC have been identified as change agents that allow organizational development and renewal of their capabilities enabling them not only to respond to changes in external environments [3], but also to renew resources [5]. The rate of renewal of organizational capabilities is unable to exceed the rate level restricted by its DC [8].

However, DC availability does not necessarily ensure for an organization to reach higher performance.
The outcomes of a number of previous researches disclosed the existence of an indirect connection between the organizational DC and its long-term performance. The connection is mediated by substantive core capabilities leveraging that, in turn, is mediated by organization strategy; DC are more likely to result in a higher organizational performance if substantive capabilities are aligned with the organization coherent strategy [6]. In this case the question remains - how the organization can identify the strategy that will result in its performance improvement and choose the right set of capabilities required to implement it in a such coherent way so that to reach the strategic goal?

Some preliminary results answering the question were received by [5], who introduced the model of the creation of DC related to entrepreneurial activities and the performance of the organization. The starting point of the model is some integrated form of organizational entrepreneurial activities to exploit the opportunities. These entrepreneurial activities determine the choice of resources and capabilities to develop and give rise to learning processes to capture knowledge from outer organizational environment. In addition to some already available selected capabilities, their combinations may include new substantive capabilities created by the organization. Substantive capabilities, combined with organizational knowledge base, define the set of the appropriate DC to reach new performance targets. In addition, the substantive capabilities and organizational knowledge base affect directly the performance of the organization.

The DC literature has some difficulties so far to address one of the most important issues from the practical point of view - namely, how the theory of strategy can explain organization top management vision to identify the strategically right capabilities to develop. The strategic problem faced by practitioners is how to pick up most promising opportunities and corresponding resources, and the capabilities to employ the opportunities, so that their accumulation would make the organization considerably more competitive. As one of the founders of the DC concept pointed out, "we still know relatively little about how firms should think of competing in the creation of capabilities" [9].

In response to the existing gap regarding how entrepreneurial activities determine the choice of resources and capabilities to develop, we use the construct of strategical entrepreneurship to set up the model of organizational strategic innovation of building dynamic and substantive capabilities and improving its performance. The main dimensions of SE construct are entrepreneurial mindset, entrepreneurial culture and entrepreneurial leadership, the strategic management of the firm's resources, as well as creativity and developing innovation, the latter being a critical outcome of its former dimensions [10].

As SE represents the combination of entrepreneurial (i.e., opportunity-seeking actions) and strategic (i.e., advantage-seeking actions) regimes to improve organizational performance, the construct seems to be well adjusted to study the ambidextrous organization that is both entrepreneurially and strategically oriented. 


\section{Latecomer and strategically entrepreneurial catch-up universities}

The goal of latecomer strategy is to attain the accelerated capability accumulation and development of an organization improving its performance, leave the group of latecomers and enter the group of leaders as soon as possible [11]. According to the combined version of RBV and DC frameworks, the latecomer organization's strategy is represented in terms of its processes, resources (positions) and capabilities. It is the identification of their deficiencies, from which a catchup organization starts accumulating its resource base to increase its level of competitiveness. Organizations at the initial stage of their resource base accumulation need a strategy corresponding to their identified current shortcomings and limitations. In organizational science emergence of capability is the outcome of integrating the specialist knowledge in the form of bases of individual members of the organization [12]. Therefore, in order to advance in its core organizational capabilities, a latecomer has to hire such individuals, who possess much knowledge in the specific area and are best prepared to create a new one. The latecomer integrates their knowledge in the most effective and purposeful way.

First stage of the latecomer strategy can include setting up initial linkage with a multinational incumbent firm by meeting its business needs, for example, by offering services under OEM contract or in any other form of low-cost production. If the latecomer has been able to find its incumbent partner, it specifies some specific niche in a global value chain and inserts itself into it. This initial position gives the latecomer an access to start integrating lacking resources from its external environment. It leverages extra resources using them to build new capabilities, as well as improves and expands the range of substantive skills. The complete iterative process of establishing links, enhancing the resource base and training within the scope of its organizational relations network, is referred to as a developmental resource leverage [11].

We introduce here a definition of the "latecomer university" (LCU) as an educational institution as a version of the latecomer firm definition adopted in the developmental literature [13].

Definition LCU satisfies following conditions:

- Strategic objective: LCU has radically updated its strategic target of advancing in global rankings and is focused on catch-up development, in contrast to its former strategy of an ordinary university without any major ambitions;

- Path dependency: LCU orientation on the development of research and advancement in the global rankings has been adopted relatively recently, in the sense that the development of the components of its resource base, having formed due to the implementation of the previous strategy, is significantly influenced by the effects of path dependency;

- The initial competitive position: LCU is characterized by relatively low or heterogeneous levels of the resource base core components, as well as low initial levels of capabilities for its development, to enhance the research capacity and advance the position occupied in the ranking;

- The resource base: despite a low original level of most organizational resources and core capabilities being insufficient for LCU to achieve the strategic objective promptly, the university seeks to remedy this deficiency by integrating and developing the lacking resources and competences, identifying and removing the barriers to their leveraging.

While for countries the "catch-up relates to the ability of a single country to narrow the gap in productivity and income vis-à-vis a leader country" [14], for the purposes of the present article the LCU catch-up means making considerable advancement in its global ranking position.

Very few LCU have been able to increase their level of core capabilities, including research capability, considerably higher than their competitors and catch up. As examples of such catch-up LCU, we can refer to the cases of advancement in ranking of research-intensive Aarhus University (Denmark), Nanyang Technological University (NTU Singapore) and École Polytechnique Fédérale de Lausanne (EPFL Switzerland). It wouldn't been enough for these LCU to employ only extant opportunities to overtake several tens or even hundreds of ranking competitors. LCU should seek new ones with a much more considerable performance improvement potential in research development. As soon as the LCU extant DC are perceived by its top management to be insufficient to impact properly the LCU's resource base, the DC themselves, in addition to other resource base components subject to renewal, need to be renewed too.

As a combination of opportunity- and advantageseeking actions, SE is especially relevant in seeking new opportunities, so a strategically entrepreneurial LCU must be more successful in advancement in rankings. Strategically entrepreneurial catch-up university (SECU) is defined here as a special type of LCU that has adopted dimensions of the SE construct. In this regard, the SECU is pursuing new more promising opportunities for developing research, so that to improve its research-based performance indicators and advance in global rankings, which reflects a rising level of its competitiveness. Hence, by unfolding definition of the SE construct dimensions [15] we arrive at our first proposition.

Proposition 1 Availability of financial, human and social capital as well as managing these organizational resources strategically combined with entrepreneurial mindset, entrepreneurial culture, entrepreneurial leadership, creativity and developing innovation increases probability for LCU to catch-up.

An entrepreneurial mindset is a growth-oriented perspective through which top managers can identify and exploit new opportunities in uncertain environment due to their cognitive abilities allowing them "to impart meaning to ambiguous and fragmented situations" [16]. Here the SECU framework has been able to deliver an answer to the question, how promising opportunities and valuable resources to make the organization 
considerably more competitive can be uncovered. From Proposition 1 it follows that SECU has a higher potential to identify new opportunities and, eventually, catch-up compared to an ordinary LCU.

Proposition 2 Acceleration of SECU research development and increase in its research performance is achieved through a substantial rise of its DC and resource base development based on the new combination of financial, human and social capital combined with strategic management of the resources, including their integration, in the course of identification and exploitation of greater opportunities.

As both LCU and SECU are specific cases of a latecomer, their development can be described in terms of iterative process of developmental resource leverage discussed above. As long as SECU organizational innovation is concerned, the iterative process of developmental resource leverage should be associated with the appropriate innovation process. In this regard, the use of the SECU framework provides us with useful variables of the SE dimensions for more comprehensive understanding of how the iterative process of LCU developmental resource leverage is running. Particularly, the proposition may be put forward regarding the dual role of DC on each iteration of the process.

Proposition 3 In the SECU iterative organizational innovation process of its developmental resource leverage, step-by-step rise of its DC represents both an outcome of the process previous iteration and, at the same time, its next iteration enabler.

The following example illustrates the enabler role of DC as the LCU ability to reconfigure its human capital resource for implementing next stage of its transformation. In 2009 preplanned reduction in staff of the Leeds University was blocked by the trade union, which demanded the president to provide assurance of the absence of job cuts and declared him a vote of no confidence in response to his refusal to provide such guarantees during the financial crisis. Thus, the inability of the LCU to carry out the reconfiguration of its human capital resulted in actual termination of its transformation program.

\section{Conclusions, implications and directions for future research}

This study presents an effort to provide an answer, from contemporary management point of view, to the question, why only few universities were able to succeed substantially so far in their global ranking advancement, while many more others fail. For this purpose it has introduced a new SECU framework, based on the combination of the RBV, DC, SE and latecomer organization concepts. To incorporate the latter concept, it has also introduced the definition of LCU as a refined RBV and DC version of latecomer definition used in relation to the university. The new SECU concept allows us to view the process of competition between LCUs as dynamic one, involving "uncertainty, struggle and disequilibrium"
[3]. The SECU inner logics articulates the importance of being ambidextrous for LCU and pursuing new potentially more favorable opportunities for research development. SECU is capable of uncovering such more promising opportunities best matched to the university and valuable resources using entrepreneurial mindset, one of SE growth-oriented perspective through which top managers can identify and exploit new opportunities in uncertain environment due to their cognitive abilities. It follows that SECU has a higher potential to identify new opportunities and, eventually, catchup compared to an ordinary LCU. Considerable increase in SECU DC and its resource base accumulation is based on the use of the new combination of financial, human and social capital combined with strategic management of these resources in the process of identification and exploitation of greater opportunities.

The answer to the question - why only few LCUs managed to succeed substantially so far in their global ranking advancement, provided in the article, may be reduced to the difficulties of transforming LCU into SECU. From the findings above, it follows that for a success of any LCU competitiveness development program it would be very helpful to have an entrepreneurial leader, like Patrick Aebischer from EPFL, in the president chair of the LCU. Anyway, LCU top managers should turn the university in ambidextrous type of organization, as its initial set of activities, as well as its initial level of $\mathrm{DC}$, are unable to ensure a significant rise of LCU research performance. The definition of an entrepreneurial university by Paul Hannon, featuring that it "creates an environment, within which the development of entrepreneurial mindsets and behaviors are embedded, encouraged, supported, incentivised and rewarded" [17] is unlikely to cover all required LCU resources and capabilities. In this regard, the SE construct perspectives provide more valuable indications for LCU managers, what set of resources and capabilities they need to accumulate, so that to transform LCU into SECU.

The new SECU concept development presented in the article represents an initial stage of the research. Henceforth the concept will be used for future case-based studies so that to specify if the SECU constituents are observable in all LCU that progressed in global rankings.

\section{References}

1. A. Gerschenkron, Economic Backwardness in Historical Perspective (Harvard University Press 1962)

2. E. Hazelkorn, University Research Management: Developing Research in New Institutions (Paris OECD Publishing 2005)

3. D. Teece, G. Pisano, A. Shuen, Strategic Manage. J., 18, 509—533 (1997) 
4. D. Leonard-Barton, Strategic Manage. J., 13, 111 (1992)

5. S. Zahra, H. Sapienza, P. Davidson, J. Manage. Stud., 43, 917-955 (2006)

6. C. Wang, P. Ahmed, Int. J. Manag. Rev., 9, 3151 (2007)

7. C. O'Reilly, M. Tushman, Res. Organ. Behav., 28, 185-206 (2008).

8. D.J. Collis, Strategic Manage. J., Winter Special Issue 15, 143-152 (1994)

9. G. P. Pisano, HBS Technology \& Operations Mgt. Unit Working Paper No. 16-036 (2015)

10. M. Hitt, R. Ireland, S. Camp, D. Sexton, Strategic Manage. J., 22, 479-491 (2001)
11. J. Mathews, D. Cho, J. World Bus. 34, 139-156 (1999)

12. R. Grant, Organ. Sci. 7, 375-387 (1996)

13. J. Mathews, Asia Pac. J. Manag., 19, 467-488, (2002)

14. J. Fagerberg, M.M. Godinho, In The Oxford Handbook of Innovation (Oxford University Press 2005)

15. R. Ireland, M. Hitt, D. Sirmon, J. Manag. 29: $963-$ 989 (2003)

16. S. Alvarez, J. Barney, In Strategic entrepreneurship: Creating a new mindset 89-105. (Oxford Blackwell Publishers 2002)

17. P. Hannon, J. Innovat. Manag., 1, 10—17 (2013) 